\title{
Memoria e infancia. Estrategias de aprendizaje en la educación primaria a partir de géneros pictóricos actuales como el surrealismo pop y sus derivados
}

\author{
Lorena Amorós Blasco lorenamo@um.es \\ María Victoria Sánchez Giner chezner@um.es
}

Universidad de Murcia, España

Reference

Resumen

Palabras clave

Abstract

Keywords
Blasco, Lorena Ambrósio; Giner, Maria Victoria Sánchez; (2012) "Memoria e infancia. Estrategias de aprendizaje en la educación primaria a partir de géneros pictóricos actuales como el surrealismo pop y sus derivados", p. 142-146. In: Barbosa, Helena; Quental, Joana [Eds]. Proceedings of the 2nd International Conference of Art, Illustration and Visual Culture in Infant and Primary Education. São Paulo: Blucher, 2015

ISSN 2318-695X, ISBN: 978-989-98185-0-7 DOI 10.5151/edupro-aivcipe-28

Desde los años 90 a la actualidad, el resurgir de géneros pictóricos que se remontan a los años 50 y 60, íntimamente ligados al contradictorio estilo "Low Brow" como el Surrealismo Pop, nos ha permitido a investigadores y artistas que trabajamos en torno a unas bases afines, reafirmarnos en nuestra forma de concebir y extrapolar nuestras ideas y proyectos. Atendiendo a esta reminiscencia de estilo, nuestra investigación pretende diseñar un programa de actividades que pueda servir después de su aplicación para demostrar cómo el imaginario de contracultura de una época puede servirnos como estrategia para construir adecuadamente un mensaje efectivo acerca de la construcción de la identidad en el niño que está en proceso de aprendizaje de un lenguaje visual artístico.

Surrealismo Pop, memoria, educación

Since the 9o's, the emergence of pictorial genres that go back to the 50's and 6o's, ed to the contradictory "Low Brow" style, such as Pop Surrealism, has allowed researchers and artists who work around similar bases, to reaffirm our way of thinking and extrapolate our ideas and projects. Following this reminiscence of style, conceived around Ed Roth's Gallery (50-60) in Los Angeles, our research aims to design a program of activities that, after its application, can serve to demonstrate how the counterculture imagery of an era, even if it sometimes satirizes the family household, may serve as an adequate strategy to build an effective message concerning the construction of identity in children who are in the process of learning the language of visual arts.

Pop Surrealism, memory, education.

\section{Introducción}

En la actualidad, el marco implícito de referencias en el que los niños van a ser socializados es asumido de un modo inconsciente, proporcionando una visión del mundo espontáneamente considerada como la única posible, donde se parte de la idea firme de una educación formalizada que determina a los niños, tanto los modos de pensar o de querer, como los modos de ver, percibir y sentir, a la vez que la ocultación de otros.

En este contexto, y teniendo en cuenta la crisis sistémica que estamos viviendo en la actualidad, el resurgir de géneros pictóricos traducidos en movimientos contemporáneos como el Surrealismo Pop, puede revelarse ante lo dado proponiendo otras maneras de comprensión de la realidad y contribuir al planteamiento de nuevas estrategias de aprendizaje.

Teniendo en cuenta que el niño comienza sus procesos de aprendizaje y expresión utilizando el lenguaje gráfico, podemos considerar este primer atisbo artístico como una herramienta 
$2^{\text {nd }}$ International Conference Art, Illustration and Visual Culture in Infant and Primary Education

\section{Diseño del Programa de Actividades a partir de géneros pictóricos actuales como el Surrealismo Pop y sus derivados contemporáneos}

\subsection{Objetivos del Programa de Actividades}

de expresión y síntesis del universo infantil en la construcción de su identidad. Además, los procesos creativos han evolucionado desde la liberación de la práctica creativa en su afán por desarrollar las particularidades del individuo, y en su inevitable y permanente interés por la subjetividad. En este sentido, nosotros concebimos la educación como un proceso y una experiencia de re-cognición y reinvención, orientado a aumentar y consolidar las capacidades individuales y colectivas de los niños mediante la recuperación y la recreación de los valores sociales y artísticos.

Para desarrollar esta perspectiva, utilizaremos las obras de artistas del SURREALISMO POP como Anthony Ausgang, Robert Williams, Mark Ryden, Glenn Barr y Marion Peck (Anderson, K., ed. 2004: 16-51) con el fin extrapolar a nuestros días temas como el surf, la animación, el rock'n'roll, los automóviles, el cómic, sin olvidar la influencia del cine de terror de monstruos desde un punto de vista chistoso y grotesco. Esta representación jocosa de la realidad/ ficción, nos permite la creación de una relación de actividades donde se estima el juego como estrategia para estimular la socialización y la conducta prosocial en niños de 6 a 12 años y acercarles, a través de este imaginario, el mundo del arte. Asimismo, desde la experiencia artística personal y tras desarrollar esta perspectiva más objetiva, nos interesa dar a conocer cómo la utilización de cierta iconografía en la ejecución de nuestra producción artística, ligada en cierta manera con el SURREALISMMO POP, hace que los niños retengan conocimientos visuales y establezcan conexiones de manera mucho más ágil, permitiéndonos explotar al máximo las referencias en torno a la ligazón existente entre nuestra memoria y la dimensión artística que queremos transmitir, para así aplicarlas de forma heterogénea a procedimiento educativos. En este sentido, incidiremos en proyectos artísticos propios como VOLUNTAD DE-FORMA y TXIKILLERS (Amorós Blasco, 2007: 3-20). Ambos proyectos artísticos son autorreferenciales y en ellos existe un empeño por definirse a través de la potencia del recuerdo de la infancia, cuestionando la auténtica biografía a partir del material fotográfico y fílmico que poseemos.

El propósito de esta investigación consiste en diseñar, aplicar y evaluar un programa de intervención visual y plástica para estimular la socialización y la conducta prosocial en niños de 6 a 12 años con el fin de facilitar la formación y el desarrollo de la identidad individual y cultural, a través de un imaginario del mundo del arte relacionado con la estética del SURREALISMO POP y sus derivados contemporáneos donde incluiremos nuestra propia obra artística.

\section{Objetivos generales:}

- Crear un espacio de aprendizaje y entretenimiento centrado en el niño.

-Desarrollar una labor formativa destinada a despertar la sensibilidad hacia los artistas y el Arte Contemporáneo.

-Fomentar el trabajo en equipo pero creando estructuras abiertas según las respuestas individuales.

-Generar experiencias que a través del juego y la imaginación promuevan actitudes de respeto.

- Ofrecer una relación de actividades para desarrollar en el aula y que sirva como complemento a la formación integral de los niños como ciudadanos activos de la sociedad y la cultura.

\section{Objetivos específicos:}

-Mejorar la convivencia en el espacio escolar y la integración en la multiculturalidad a través del Arte Contemporáneo. 
$2^{\text {nd }}$ International Conference Art, Illustration and Visual Culture in Infant and Primary Education $2^{\circ}$ Congreso Internacional

Arte, Ilustración y Cultura Visual en Educación Infantil y Primaria
Congresso Internacional

de Arte, llustracão e Cultura Visual

na Educação Infantil e Primária
1.2 Metodología

\subsection{Relación de Actividades}

Figuras 1, 2 y 3 . A la izquierda: Elena (7 años) durante el visionado de las imágenes en la pizarra digital. (11 de mayo de 2012). Colegio Joaquín María López, Villena, España. Fuente: propia. En el centro: la clase de segundo de primaria escogiendo una imagen entre cuatro repartidas. (11 de mayo de 2012). Colegio Joaquín María López, Villena, España. Fuente: propia. A la derecha: Juan (8 años) mostrando la imagen preferida (11 de mayo de 2012). Colegio Joaquín María López, Villena, España. Fuente: propia.
-Potenciar y dar prioridad al misterio y la fantasía del niño.

-Experimentar a través de las imágenes los elementos que configuran el lenguaje artístico posibilitando la expresión y comunicación de hechos, sentimientos, emociones y vivencias.

-Saber contextualizar en términos de cultura cada una de las posibilidades del Arte Contemporáneo.

-Desarrollar el conocimiento sobre las estrategias mediáticas para el aprendizaje visual.

-Capacitarles para que cuestionen aquellos productos mediáticos que consumen.

-Poder encontrar en el arte un lugar privilegiado desde el que construir una mirada crítica hacia la realidad y distinguirlo como un entorno en el que es posible plantear preguntas y encontrar respuestas.

La metodología que se aplicará será aquella de carácter activo y lúdico, vivencial y socioafectivo, basada en el aprendizaje por descubrimiento, significativo y lógico, creando un clima que motive la participación y la continua experimentación con el arte, tratando de despertar capacidades sensibles y críticas en el niño.

Nuestra intención será buscar alternativas concretas de transmisión unidireccional del conocimiento: queremos que los niños asuman el protagonismo y se impliquen en el proceso de enseñanza y aprendizaje.

\section{ACTIVIDAD I.}

Fase 1.Explicar al niño en el aula las actividades que van a desarrollar a partir del visionado de las imágenes en la pizarra digital, correspondientes a cuatro grupos:

Grupo A: Artistas de las Vanguardias Artísticas (Picasso, Munch, Cezanne, Gauguin...)

Grupo B: Imágenes neutras

Grupo C: Artistas del Surrealismo Pop (Anthony Ausgang, Robert Williams, Mark Ryden, Glenn Barr y Marion Peck)

Grupo D: Imágenes de nuestra producción artística

Fase 2. En esta primera toma de contacto, y mediante una serie de preguntas combinadas de carácter convergente, divergente y crítico, estimularemos al niño en la observación del color, la forma y el significado de las mismas.
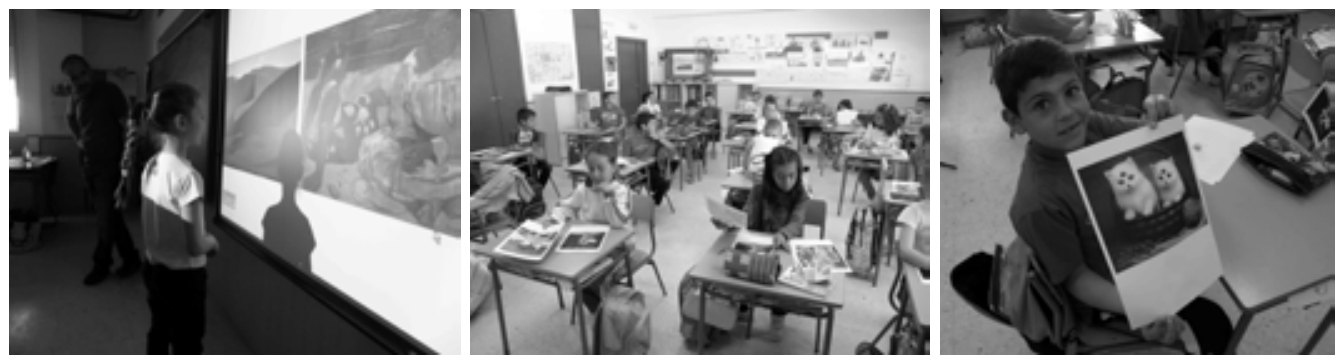

ACTIVIDAD ॥.

Dado que el niño, alrededor de los ocho años, puede interpretar lo que sucede en una figura, creciendo su comprensión de las interrelaciones, la causalidad y la interdependencia, poniendo asimismo más atención a los detalles y utilizando el recurso de la acumulación para llevar a cabo la actividad relacionada con nuestra propuesta, repartiremos entre alumnos, de forma individual, cuatro imágenes correspondientes a los cuatro grupos seleccionados:

Fase 1: Una vez repartidas, se le pedirá a cada niño de manera individual que vaya prescindiendo de las distintas imágenes hasta quedarse únicamente con una. Tras esta selección final, donde el 
2nd International Conference Art, Illustration and Visual Culture in Infant and Primary Education $2^{\circ}$ Congreso Internaciona

Arte, Ilustración y Cultura Visual en Educación Infantil y Primaria
${ }^{\circ}$ Congresso Internacional

de Arte, Ilustração e Cultura Visual

na Educação Infantil e Primária
Figuras 4, 5 y 6 . A la izquierda: Resumen de Juan (8 años) acerca del porqué de su elección (11 de mayo de 2012). Colegio Joaquín María López, Villena, España. Fuente: propia. En el centro: Nadia leyendo su resumen delante de los compañeros (11 de mayo de 2012). Colegio Joaquín María López, Villena, España. Fuente: propia. A la derecha: Miguel y Alonso tras realizar el dibujo que atiende a lo que le ha sugerido la imagen escogida. (11 de mayo de 2012). Colegio Joaquín María López, Villena España. Fuente: propia. niño contará con la imagen preferida, cada uno de ellos escribirá un resumen del porqué de su elección y lo leerá delante de sus compañeros.

Fase 2: Se realizará un mural con todas las imágenes preferidas de cada niño.

Fase 3: Se le pedirá a cada niño que elabore un dibujo con el material que prefiera y que atienda a lo que le ha sugerido la imagen escogida. Con todos los dibujos se llevará a cabo un segundo mural correlativo al primero para generar preguntas y crear un diálogo donde se considere la conciencia crítica de los niños ante estas imágenes, estableciendo relaciones entre la información y sus vivencias personales.
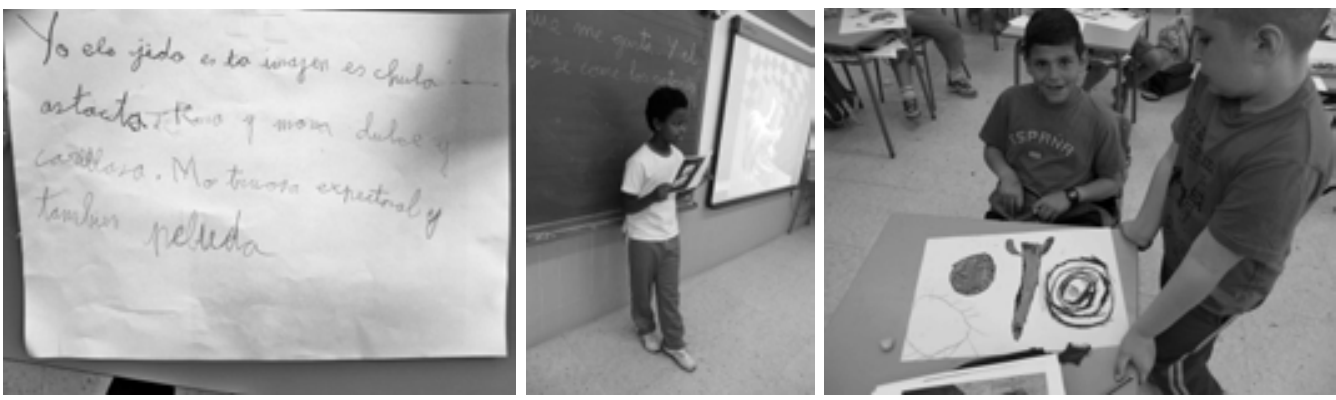

ACTIVIDAD III. RELACIÓN CON ARTISTAS.

Las actividades anteriores fomentarán el intercambio de experiencias descriptivas, analíticas, interpretativas de los distintos grupos en los que se desarrolle este plan de actividades, de modo que se invitará a un artista contemporáneo (Lorena Amorós) y relacionado con el SURREALISMO POP para cerrar el programa y transmitirle a los niños que:

- Las imágenes son representaciones parciales de la realidad.

- Las imágenes nos dan visiones de un sin fin de cuestiones: construcción de género, de valores, de juicios morales, etc.

- La estética de esas imágenes está al servicio del contenido que se quiere transmitir.

- Los productos mediáticos que consumen tienen que ver con el arte y no están fuera de su vida cotidiana.

La importancia de la presente investigación radica en proponer una vinculación innovadora de un área del acervo cultural poco explotado en la educación como es el arte contemporáneo. En este sentido, la aplicación de nuestro programa de actividades se desarrolló en el Colegio Joaquín María López de Villena (Alicante) y en el aula de niños de segundo de primaria el día 11 de mayo de 2012. Durante su aplicación, observamos cómo estas particulares imágenes artísticas relacionadas con el SURREALISMO POP y sus derivados contemporáneos, en este caso, nuestra propia obra, tenían una mayor aceptación en relación al resto de los grupos de imágenes propuestos, y constituían en su mayoría las imágenes escogidas para el primer mural realizado en el aula por ser las preferidas de estos niños. Percibimos que la reivindicación del imaginario cultural de este género pictórico y la obra presentada por el artista (Lorena Amorós) fomentaban mayor número de comentarios y nos servía para no proteger a los niños de los estímulos que, en ocasiones, se consideran negativos antes de su visualización. Por lo que consideramos que ha sido positivo no anticiparnos a su experiencia, pues los posibles miedos o rechazos no se reproducen de igual modo que en la vida cotidiana, y las respuestas pueden encauzarse de forma constructiva.

Asimismo, advertimos que el imaginario propuesto favorecía al niño en la formación de su identidad cultural debido a que el arte en general y, el Surrealismo Pop junto con nuestra obra en particular, tiene un componente estético y sensitivo que le permite ser un facilitador y detonador de experiencias, sensaciones y sentimientos (inteligencia emocional). Creemos firmemente que, a través de las actividades que propusimos, de carácter visual y artístico, el niño pudo comenzar a comprender e iniciar una incipiente reflexión acerca de los componentes 
$2^{\text {nd }}$ International Conference Art, Illustration and Visual Culture in Infant and Primary Education
Figuras 7 y 8 . A la izquierda: Mural resultante de las imágenes preferidas de cada niño (11 de mayo de 2012). Colegio Joaquín María López, Villena, España. Fuente: propia. A la derecha: Mural realizado con todos los dibujos de los niños tras las distintas actividades (11 de mayo de 2012). Colegio Joaquín María López, Villena, España. Fuente: propia. sociales y morales de su educación y con ello, mejorar las formas de convivencia escolar en su entorno. Por ello, partiendo de la consideración de que las obras de arte, en cuanto formas de expresión de los artistas, entrañan además de la transmisión de distintas sensaciones y sentimientos que el niño-espectador puede captar básicamente por la intervención del gusto y la sensibilidad; creemos igualmente que las distintas expresiones artísticas son textos que nos "hablan" desde una época, un contexto cultural, social, político, histórico y personal, peculiar en cada una de sus concretizaciones, por lo que pensamos que las obras de arte no son únicamente expresión de la interioridad de un sujeto-artista, sino más aún," textos para la percepción sensible y la interpretación conceptual" (Gadamer, 2000: 67).

En base a estos preceptos, podemos constatar que las obras artísticas citadas en nuestra investigación, así como la relación directa en el aula con el artista, han sido medios didácticos eficaces para ayudarle al niño en la comprensión del plano estético y la sensibilidad artística, así como constituir una rica fuente de análisis y reflexión a partir de sus contenidos explícitos en la formación de su identidad cultural. Como hemos corroborado, las imágenes pertenecientes al Surrealismo Pop y sus derivados contemporáneos, les suscitaban comentarios divertidos, relacionados con su familia, los dibujos animados de la televisión y sus experiencias en el entorno social.
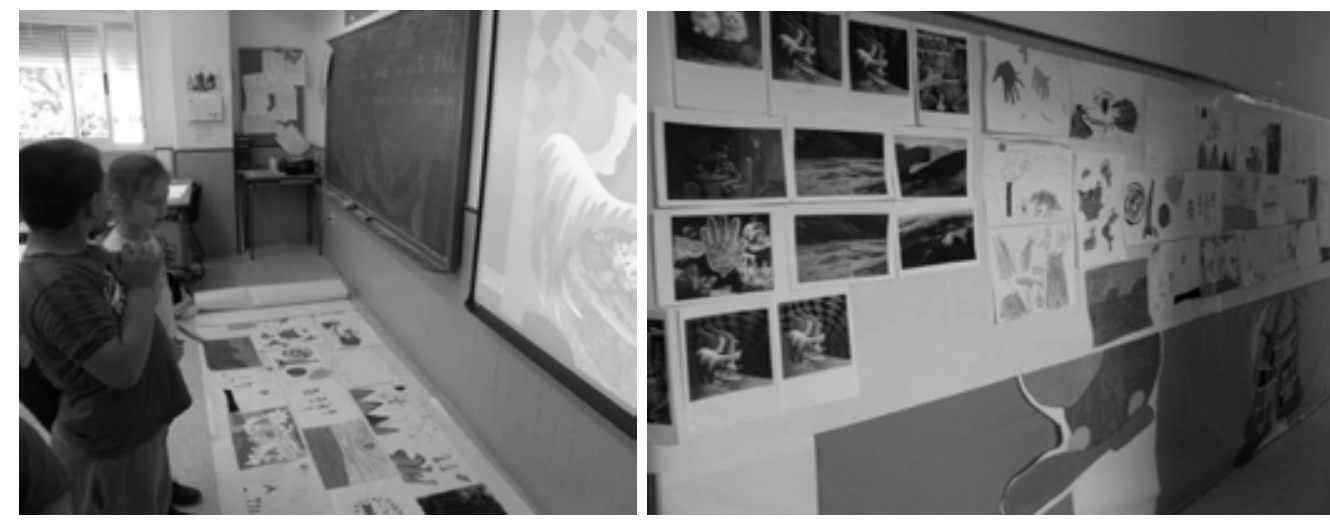

De modo que nuestra evaluación es positiva y creemos necesario volver a repetirla en distintas aulas y con niños de edades diferentes para poder subsanar posibles errores y, por otra parte, constatar cómo el arte que nos proporciona el Surrealismo Pop, así como la experiencia con los artistas, ayudan al niño a sumergirse en el viaje interior que el ser humano debe realizar para llegar a ese yo independiente de las condiciones existenciales, un yo que nos proporciona una comprensión de la realidad más ética y totalizadora que la manera fragmentaria, mecanicista y utilitarista que tenemos de abordarla.

\section{Referencias bibliográficas}

Gadamer, H-G. (2000) La educación es educarse. Barcelona. Paidós, 2000, p. 67.

Kincheloe, J. (2004). Critical Pedagogy. NY: Peter Lang.

Anderson, K., ed. (2004) Pop Surrealism. The Rise of Underground art. San Francisco: Last Gap.

Amorós Blasco L. (2007) Restos de familia. Lo entrañable de las entrañas. Alicante: Museo de la Universidad de Alicante (MUA)

Museo de Bellas Artes de Murcia (MUBAM), ed. (2010) Lorena Amorós. Reliquias desentrañables. Murcia: Publicaciones MUBAM. 